\title{
PERSEPSI MAHASISWA MENGENAI LINGKUNGAN BELAJAR KLINIK DAN MOTIVASI BELAJAR PADA SUATU PROGRAM STUDI NERS
}

\author{
Suryani*, Rossi Sanusi**, Tridjoko Hadianto** \\ *Program Studi Ners, Universitas Aisyiah, Yogyakarta - INDONESIA \\ **Fakultas Kedokteran, Universitas Gadjah Mada, Yogyakarta - INDONESIA
}

\begin{abstract}
Background: Effective learning should be based on an understanding of how students learn. Students who are well adjusted will be actively involved in learning. The role of motivation will encourage individuals to have appropriate strategies to guide their learning, to depthly process the information which in turn produces better learning achievement. Environment creates a learning atmosphere that influences students learning motivation. This study was aimed to find out the correlation between students' perception of clinical learning environment and learning motivation.
\end{abstract}

Method: The study used quantitative method with cross sectional approach. 70 Ners students of Aisyiyah University of Yogyakarta academic year 2015/2016 answered the Clinical Learning Environment and Supervision (CLES) and Motivated Strategies for Learning Questionnaire (MSLQ) questionaires. Pearson test was used to analyze the data.

Results: Most of the students (77.1\%) showed positive perception about the clinical learning environment. They were more likely to be motivated extrinsically than intrinsically. The highest value of task value motivation subscales shows a mean value of $5.79(\mathrm{SD}=+0.67)$ while the lowest value in the anxiety test sub-scale shows a mean of $3.52(\mathrm{SD}=+1.23)$. The clinical learning environment of the head of the room leadership style sub-scale has a weak positive correlation with the motivation to learn $(r=0.297$ and $p=0.012)$.

Conclusion: There is a weak positive correlation between students' perception of clinical learning environment and learning motivation. Clinical learning environment needs to be well prepared to meet the needs and improve students learning motivation.

Keywords: clinical learning environment, learning motivation, nursing students

\section{ABSTRAK}

Latar belakang: Pembelajaran yang efektif harus didasarkan pada pemahaman tentang bagaimana mahasiswa belajar. Mahasiswa yang menyesuaikan diri dengan baik akan terlibat secara aktif dalam pembelajaran. Peran motivasi akan mendorong individu memiliki strategi yang sesuai untuk mengarahkan belajarnya, memperoses informasi dengan mendalam yang kemudian menghasilkan pencapaian belajar yang lebih baik. Lingkungan menciptakan suasana belajar yang mempengaruhi motivasi mahasiswa. Penelitian ini bertujuan mengetahui hubungan antara persepsi mahasiswa mengenai lingkungan belajar klinik dan motivasi belajar.

Metode: Penelitian ini menggunakan metode kuantitatif dengan rancangan cross sectional. Sebanyak 70 mahasiswa profesi ners Universitas 'Aisyiyah Yogyakarta angkatan tahun 2015/2016 mengisi kuisioner Clinical Learning Environment and Supervision (CLES) dan Motivated Strategies for Learning Questionnaire (MSLQ). Data dianalisis dengan uji korelasi Pearson.

Contact: suryani.ar14@gmail.com 
Hasil: Sebagian besar mahasiswa (77, 1\%) menunjukkan penilaian yang positif mengenai lingkungan belajar klinik. Mahasiswa lebih cenderung termotivasi secara ekstrinsik dibandingkan secara instrinsik. Nilai tertinggi motivasi pada sub skala task value dengan mean 5,79 $(\mathrm{SD}= \pm 0,67)$ sedangkan nilai terendah pada sub skala test anxiety dengan mean 3,52 $(\mathrm{SD}= \pm 1,23)$. Lingkungan belajar klinik pada sub skala gaya kepemimpinan kepala ruang memiliki hubungan positif yang lemah dengan motivasi belajar ( $\mathrm{r}$ $=0,297$ dan $\mathrm{p}=0.012$ ).

Kesimpulan: Terdapat hubungan positif yang lemah antara persepsi mahasiswa mengenai lingkungan belajar klinik dan motivasi belajar mahasiswa. Lingkungan belajar klinik perlu disiapkan dengan baik untuk memenuhi kebutuhan dan meningkatkan motivasi belajar mahasiswa.

Kata kunci: Lingkungan belajar klinik, motivasi belajar, profesi Ners

\section{PENDAHULUAN}

Pembelajaran yang efektif harus didasarkan pada pemahaman tentang bagaimana mahasiswa belajar. Perkembangan teori belajar dari perspektif konstruktivisme menyebutkan bahwa pengetahuan tidak pasif diterima oleh invididu tetapi dibangun oleh individu. Individu akan belajar lebih baik apabila mereka secara aktif mengkonstruksi pengetahuan dan pemahaman mereka. ${ }^{1-3}$

Mahasiswa yang menyesuaikan diri dengan baik akan terlibat dalam pembelajaran. Keterlibatan mahasiswa dalam konteks pendidikan merujuk pada waktu, energi dan sumber-sumber yang dicurahkan oleh mahasiswa untuk kegiatan yang dirancang untuk meningkatkan pembelajaran. ${ }^{3}$ Mahasiswa membutuhkan energi yang mendorong agar dapat terlibat aktif dalam proses belajar. Peran motivasi akan mendorong individu mau dan memiliki strategi yang sesuai untuk mengarahkan belajarnya, memperoses informasi dengan mendalam yang kemudian menghasilkan pencapaian belajar yang lebih baik. ${ }^{5,6}$

Pertanyaan penting institusi pendidikan bagi mahasiswa adalah "bagaimana mahasiswa mengarahkan proses belajarnya dan apa yang dapat dilakukan oleh institusi untuk membantu usaha tersebut?". Institusi perlu mengidentifikasi bagaimana cara mendorong mahasiswa agar mereka bisa mengatur proses belajar mereka sendiri, mengevaluasi tingkat pengetahuan yang telah dicapai dan melihat area yang membutuhkan perbaikan termasuk menyediakan lingkungan belajar yang kondusif yang mendukung mahasiswa. ${ }^{3}$

Lingkungan belajar menciptakan suasana belajar yang mempengaruhi motivasi mahasiswa dan strategi belajar. Motivasi akan mengarahkan perilaku dan usaha mahasiswa yang terlihat dari cara mahasiswa memilih suatu strategi belajar tertentu (surface approach atau deep approach). Pemilihan strategi belajar tersebut kemudian mempengaruhi hasil belajar yang didapatkan. Untuk itu, diperlukan lingkungan belajar yang baik yang mendukung proses belajar mahasiswa. ${ }^{7}$

Penilaian mahasiswa terhadap lingkungan belajar mereka di berbagai tempat berbeda-beda. Tidak semua tempat praktek mampu memberikan lingkungan pembelajaran yang positif bagi mahasiswa. Perbedaan ini dikaitkan dengan adanya perbedaan karakteristik sumber daya dan tehnologi yang ada di setiap lahan praktek dan perkembangan teknologi di setiap Negara. Penelitian Rahmani ${ }^{8}$ di Universitas Tabriz dengan menggunakan Clinical Learning Environment Inventory (CLEI) menunjukan pada skala personalisasi, keterlibatan, inovasi, kepuasan, dan individualisasi dinilai negativ oleh mahasiswa sedangkan skala orientasi tugas dinilai positif. Adanya gap pengetahuan dan gap profesi di klinik menjadi sumber stress bagi mahasiswa. ${ }^{9}$ Tuntutan pelayanan dan manajerial di lahan menjadikan pembimbing sibuk dengan pekerjaan rutin sehari-hari yang berdampak pada kurangnya waktu bimbingan. ${ }^{10}$ Kurangnya waktu bimbingan dan kesempatan praktek juga disebabkan banyaknya mahasiswa yang praktek dalam satu bangsal dari 
berbagai institusi pendidikan. ${ }^{11}$ Seting ruangan dan jenis kompetensi yang berbeda pada saat rotasi stase menimbulkan kecemasan dan rasa tidak percaya diri jika tidak ada pengamatan dan pendampingan dengan pembimbing. ${ }^{10-12}$

Pendidikan klinik Program Studi Ners Universitas 'Aisyiyah Yogyakarta diselenggarakan setelah tahap akademik dengan beban 34 sks yang terdiri dari 9 rotasi regular dan 1 rotasi program peminatan. Mahasiswa ditempatkan pada berbagai seting rumah sakit baik dalam rawat inap dan poliklinik, puskesmas, panti sosial, keluarga dan komunitas. Selama kurun waktu pelaksanaan program pendidikan ners dari tahun 2008, institusi telah beberapa kali melakukan evaluasi mengenai penyelenggaraan pendidikan profesi. Evaluasi lebih berfokus pada kualitas penyelenggaraan profesi ners pada aspek pembimbing, ketersediaan sumber belajar di lahan praktek dan dokumen perangkat pembelajaran.

Namun evaluasi mengenai lingkungan belajar klinik yang digunakan mahasiswa sebagai tempat belajar belum dilakukan secara rinci termasuk evaluasi faktor motivasi mahasiswa yang memegang peranan penting dalam proses belajar mereka. Mengingat lingkungan belajar klinik mencakup segala sesuatu yang berada di sekeliling mahasiswa yang dibutuhkan untuk proses belajar dari aspek kurikulum, seting klinik, pembimbing, staf, pasien, iklim belajar dan mahasiswa itu sendiri. Komponen tersebut menjadi konteks sosial yang komplek yang berinteraksi satu sama lain dan dapat menaikkan maupun menurunkan motivasi belajar mahasiswa. Melihat perlunya evaluasi tersebut, maka penelitian ini dilakukan dengan tujuan menilai kualitas lingkungan belajar klinik, menilai motivasi mahasiswa dan mengetahui hubungan antara persepsi mahasiswa mengenai lingkungan belajar klinik dan motivasi belajar. Institusi dapat melihat komponen-komponen yang perlu ditindaklanjuti dan yang masih perlu diperbaiki untuk meningkatkan kualitas belajar mahasiswa.

\section{METODE}

Penelitian ini menggunakan metode kuantitatif dengan rancangan cross sectional. Responden penelitian meliputi seluruh mahasiswa yang sedang menempuh tahap Profesi Ners Universitas 'Aisyiyah Yogyakarta tahun 2015/2016 gerbong ketiga sebanyak 108 mahasiswa, melalui stase lingkungan klinik, bersedia jadi responden dengan mengisi inform consent dan mengembalikan isian kuisioner.

Persepsi mengenai lingkungan belajar klinik dinilai dengan instrumen Clinical Learning Environment and Supervision (CLES) yang dikembangkan oleh Saarikoski et al. ${ }^{13}$ CLES terdiri dari 5 subskala yaitu persepsi suasana ruang perawatan, gaya kepemimpinan kepala ruang, nilai-nilai keperawatan di ruangan, nilai-nilai pembelajaran di ruangan dan hubungan supervisi. Kuesioner CLES ini telah dilakukan uji validitas dan reliabilitas oleh Saarikoski et al, ${ }^{13}$ dengan construct validity antara 0,74-0,95 dan reliabilitas dengan nilai cronbach alfa 0,78 . Instrumen ini telah diterjemahkan kedalam versi bahasa Indonesia oleh $\operatorname{Hasan}^{14}$ dan telah dilakukan uji validitas instrument CLES versi bahasa Indonesia ini dengan hasil $r>0,3$ yaitu berkisar antara 0,322-0,854 dan uji reliabilitas dengan hasil nilai alfa sebesar 0,920. Berdasarkan hasil tersebut instrument CLES yang telah diterjemahkan dalam bahasa Indonesia dinilai valid dan reliabel.

Motivasi diukur dengan menggunakan instrumen Motivated Strategies for Learning Questionnaire (MSLQ) yang dikembangkan oleh Pintrich et al. ${ }^{15}$ Penelitian ini hanya mengambil bagian 1 dari MSLQ yaitu 31 pernyataan yang untuk mengukur motivasi dengan 6 subskala yaitu instrinsik goal orientation, ekstrinsik goal orientation, task value, control of learning belief, self-efficacy for learning and performance, test anxiety. Kuesioner MSLQ ini menggunakan instrumen yang telah digunakan oleh penelitian sebelumnya dan telah diterjemahkan dalam versi Bahasa Indonesia oleh Lisiswati ${ }^{16}$ dan telah dilakukan uji validitas dan reliabilitas dengan construct validity dengan hasil $\mathrm{r}>0,3$ dan uji reliabilitas dengan hasil nilai alfa berkisar antara $0,502-0,781$. Berdasarkan hasil tersebut instrumen MSLQ yang telah diterjemahkan dalam bahasa Indonesia dinilai valid dan reliabel.

Sebelum digunakan pada penelitian ini, instrumen CLES dan MSLQ dilakukan uji keterbacaan dan kefahaman pada empat mahasiswa yang tidak 
terlibat sebagai responden penelitian untuk melihat apakah butir-butir pernyataan dalam instrumen mudah dipahami atau tidak. Keempat mahasiswa menyatakan seluruh butir pernyataan pada kedua instrumen mudah dipahami.

Pengumpulan data dalam penelitian ini berlangsung bulan Agustus 2016. Data penelitian berasal dari data primer (melalui pengisian kuisioner oleh mahasiswa yang menjadi subyek penelitian). Sebelum membagikan kuesioner, peneliti memberikan informasi mengenai kegiatan penelitian yang sedang dilakukan antara lain 1) tujuan penelitian dan kepentingannya bagi peneliti, institusi dan mahasiswa; 2) mahasiswa diberikan kebebasan untuk mau terlibat atau tidak dalam mengisi kuesioner; 3) pengisian kuesioner tidak memberikan pengaruh apapun bagi mahasiswa terkait penilaia stase; 4) meminta mahasiswa mengisi kuisioner sesuai keadaan sebenarnya yang dirasakan dan tidak ada jawaban benar atau salah; 5) menjelaskan jenis kuisioner yang diisi dan cara pengisian kuesioner; 6) Menyampaikan bahwa informasi penelitian secara detail ada di lembar informasi yang diserahkan bersama kuesioner. Setelah informasi dijelaskan, selanjutnya peneliti meminta mahasiswa untuk menandatangani lembar persetujuan (inform consent).

Dalam proses pengambilan data, peneliti mengidentifikasi mahasiswa dan lokasi praktek yang digunakan berdasarkan kalender akademik profesi, tahun ajaran 2015/2016. Kemudian menghubungi salah satu mahasiswa di setiap lokasi untuk menentukan waktu dimana calon responden bisa ditemui dengan tanpa mengganggu aktivitas mahasiswa dalam ruangan. Mahasiswa yang sedang menjalani praktek di lokasi yang jauh, peneliti mengirimkan kuesioner melalui email meminta untuk mengirimkan kembali kuesioner yang sudah diisi melalui email.

Pengolahan data diawali dengan melakukan deskripsi karakteristik responden penelitian. Selanjutnya untuk melihat hubungan antara persepsi lingkungan belajar klinik dan motivasi belajar serta melihat hubungan antara masingmasing sub skala variabel lingkungan belajar klinik dan motivasi menggunakan uji statistik korelasi Pearson.

\section{HASIL DAN PEMBAHASAN}

Penelitian ini melibatkan sebanyak 70 (64,8\%) mahasiswa profesi ners Universitas 'Aisyiyah Yogyakarta angkatan tahun 2015/2016. Karakteristik responden yang diidentifikasi yaitu jenis kelamin, tempat tinggal, minat menjadi perawat, dan pilihan karir selanjutnya (Tabel 1). 
Tabel 1. Distribusi karakteristik responden

\begin{tabular}{|c|c|c|c|}
\hline & Karakteristik & Frekuensi & Persentasi \\
\hline \multirow{2}{*}{ Jenis Kelamin } & Laki-laki & 14 & 20,0 \\
\hline & Perempuan & 56 & 80,0 \\
\hline \multicolumn{2}{|l|}{ Total } & 70 & 100 \\
\hline \multirow{4}{*}{ Tempat tinggal } & Dengan orang tua & 16 & 22,9 \\
\hline & Dengan saudara & 8 & 11,4 \\
\hline & Kos & 45 & 64,3 \\
\hline & Lainnya & 1 & 1,4 \\
\hline \multicolumn{2}{|l|}{ Total } & 70 & 100 \\
\hline \multirow{4}{*}{ Minat perawat } & Keinginan orang tua & 12 & 17,1 \\
\hline & Kemudahan mencari pekerjaan & 21 & 30,0 \\
\hline & Kecintaan pada profesi & 25 & 35,7 \\
\hline & Lainnya & 12 & 17,1 \\
\hline \multicolumn{2}{|l|}{ Total } & 70 & 100 \\
\hline \multirow{5}{*}{ Pilihan karir } & Perawat klinik & 14 & 20,0 \\
\hline & Perawat spesialis & 24 & 34,3 \\
\hline & Pengajar & 13 & 18,6 \\
\hline & Praktek mandiri & 12 & 17,1 \\
\hline & Lainnya & 7 & 10,0 \\
\hline \multicolumn{2}{|l|}{ Total } & 70 & 100 \\
\hline
\end{tabular}

Mahasiswa profesi Ners Universitas 'Aisyiyah Yogyakarta memiliki persepsi cenderung positif terhadap lingkungan belajar klinik (mean \pm SD $=3,79 \pm 0,61)$. Dari 70 mahasiswa terdapat 54 mahasiswa $(77,1 \%)$ menunjukkan penilaian yang cenderung positif dan sebanyak 16 mahasiswa $(22,8 \%)$ menunjukkan penilaian yang cenderung negatif.
Tabel 2 menunjukkan bahwa nilai rerata persepsi mahasiswa profesi Ners pada tiap sub skala instrumen CLES cenderung positif (skala 1-5). Nilai tertinggi persepsi mahasiswa mengenai lingkungan belajar klinik adalah pada sub skala gaya kepemimpinan kepala ruangan (mean $\pm \mathrm{SD}=$ $3,89 \pm 0,57)$ sedangkan nilai terendah adalah pada sub skala suasana ruang perawatan (mean $\pm \mathrm{SD}=$ $3,69 \pm 0,62)$.

Tabel 2. Deskripsi tiap sub skala lingkungan belajar klinik

\section{Dimensi lingkungan pembelajaran klinik}

Suasana ruang perawatan

Gaya kepemimpinan kepala ruang

Nilai-nilai perawatan di ruangan

Nilai-nilai pembelajaran di ruangan

Hubungan supervisi

\section{Mean}

3.69

3.89

3.79

3.81

3.78
Standar Deviasi

0.62

0.57

0.60

0.64

0.61
Nilai rerata motivasi belajar mahasiswa profesi Ners Universitas 'Aisyiyah Yogyakarta adalah 5,48 (SD $= \pm 0,78)$. Nilai rerata motivasi mahasiswa profesi
Ners pada tiap sub skala instrumen MSLQ (skala 1-7) ditunjukkan pada tabel 3. 
Tabel 3. Deskripsi tiap sub skala motivasi belajar

\begin{tabular}{lcc}
\multicolumn{1}{c}{ Dimensi Motivasi Belajar } & Mean & Standar Deviasi \\
Instrinsic goal orientation & 5,82 & 0,67 \\
Extrinsicgoal orientation & 5,90 & 0,79 \\
Task value & 5,97 & 0,67 \\
Control of learning belief & 5,79 & 0,76 \\
Self-efficacy for learning and performance & 5,89 & 0,56 \\
Test anxiety & 3,52 & 1,23 \\
\hline
\end{tabular}

Nilai tertinggi adalah pada sub skala task value dengan mean 5,97. Sedangkan nilai terendah motivasi mahasiswa adalah pada sub skala test anxiety dengan mean 3,52. Nilai rerata sub skala instrinsic goal orientation adalah 5,82 $(\mathrm{SD}= \pm 0,67)$ dan sub skala extrinsic goal orientation adalah 5,90 $(\mathrm{SD}= \pm 0,79)$.

Hubungan persepsi mengenai lingkungan belajar klinik dan motivasi belajar dengan uji korelasi Pearson didapatkan hubungan positif dengan kekuatan hubungan lemah $(r=0,255)$. Signifikansi hubungan dinilai bermakna secara statistik dengan $\mathrm{p}=0,033(\mathrm{p}<0,05)$. Analisis hubungan masingmasing sub skala lingkungan belajar klinik dan motivasi belajar didapatkan sub skala lingkungan belajar klinik yang memiliki hubungan dengan motivasi adalah gaya kepemimpinan kepala ruangan. Hubungan tersebut positif dan kekuatan hubungan lemah $(r=0,297)$ dengan tingkat signifikansi $p=0.012(p<0,05)$. Sedangkan sub skala suasana ruang perawatan, nilai-nilai perawatan di ruangan, nilai-nilai pembelajaran di ruangan dan hubungan supervisi tidak memiliki hubungan yang bermakna dengan motivasi.

Hasil penelitian ini sejalan dengan beberapa penelitian sebelumnya mengenai variable yang mendukung pembelajaran di klinik. Saarikoski \& Leino-Kilpi ${ }^{13}$ menyatakan lingkungan pembelajaran yang baik ditunjukkan dengan gaya manajemen yang demokratis dan kepala ruang memperhatikan kebutuhan staf dan mahasiswa secara fisik dan emosional yang mendukung terciptanya proses belajar efektif. Selain itu, suasana ruangan yang positif juga menjadi ciri penting dari lingkungan klinik yang baik. ${ }^{13}$
Haggerty, Holloway, dan Wilson dalam Kim et al. ${ }^{10}$ mengidentifikasi empat faktor keefektifan pembimbing yang mendukung pengembangan kompetensi dan kenyamanan mahasiswa. Faktorfaktor tersebut yaitu akses mahasiswa terhadap preceptor, hubungan preceptor dengan mahasiswa, kesiapan peran pembimbing dan keseluruhan budaya bimbingan yang dibentuk.

Kepala ruangan memiliki tanggungjawab besar dalam pelayanan keperawatan di ruangan. Kepala ruang menjadi pemimpin yang mengarahkan dan mengorganisir jalannya proses diruangan untuk mencapai tujuan pelayanan. Dalam hal ini, peran manajer ruangan menjadi sangat penting dalam menciptakan suasana yang positif bagi siapa saja yang terlibat dalam aktifitas ruangan, termasuk mengatur penyediaan kebutuhan belajar bagi mahasiswa. Keberhasilan berjalannya sistem di ruangan, penyelesaian situasi sulit dan pembentukan iklim positif sangat tergantung kemampuan leadership dari kepala ruangan. ${ }^{17}$

Hasil penelitian ini menunjukkan bahwa mahasiswa profesi Ners menyatakan terdapat suasana yang positif pada lingkungan klinik, adanya hubungan kekeluargaan dan ruangan dianggap sebagai lingkungan belajar yang baik oleh mahasiswa. Hal lain yang mendukung pembelajaran mahasiswa adalah adanya hubungan supervisi dari pembimbing. Pembimbing klinik menunjukkan sikap yang positif terhadap supervisi. Supervisi didasarkan pada hubungan persamaan dan mendukung belajar, saling menghormati dalam hubungan supervisi dan hubungan supervisi dikarakteristikan dengan perasaan saling percaya. 
Selain kondisi yang positif, hasil penelitian ini juga mengidentifikasi adanya masalah ketidaknyamanan mahasiswa selama di klinik. Mahasiswa tidak nyaman untuk mengambil bagian dalam diskusi selama pertemuan staf dan mahasiswa merasa kurang merasa nyaman untuk ikut terlibat pada diskusi diruangan dan di awal shift. Hasil tersebut dimungkinkan karena ketidaksiapan mahasiswa untuk terlibat sebagai bagian dari tim perawatan di ruangan. Hal ini sejalan dengan penelitian Hasan ${ }^{14}$ yang menyebutkan bahwa kenyamanan mahasiswa dalam diskusi dan berada di awal shift juga dinilai negatif oleh mahasiswa.

Elgicil \& Sari ${ }^{18}$ menyebutkan lingkungan klinik sering menimbulkan ketidaknyamanan bagi mahasiswa. Mahasiswa memasuki lingkungan asing yang tidak bisa ia kontrol. Ketidaknyamanan mahasiswa di lingkungan klinik disebabkan antara lain kecemasan saat datang pertama kali, ketakutan melakukan kesalahan, kekhawatiran muncul kritik dari lingkungan. Adanya gap pengetahuan dan gap profesi. ${ }^{9}$ Ketidakcukupan panduan dan beban kerja berlebih juga menjadi sumber stress mahasiswa. ${ }^{11}$

Hasil penelitian pada variabel motivasi belajar menunjukan nilai sub skala task value dinilai paling tinggi. Hal ini berarti mahasiswa memiliki tingkat ketertarikan yang baik terhadap belajarnya dan merasa belajar atau tugas yang dikerjakan menjadi hal yang penting dan bermanfaat bagi mahasiswa. Sedangkan nilai terendah motivasi mahasiswa adalah pada sub skala test anxiety yang berarti mahasiswa profesi ners memiliki kecemasan tinggi pada saat ujian. Terkait alasan yang mendorong mahasiswa untuk belajar, ditemukan bahwa mahasiswa profesi Ners lebih cenderung termotivasi secara ekstrinsik dibandingkan secara instrinsik meskipun perbedaan nilainya tidak jauh berbeda.

Hasil ini sama dengan yang ditemukan oleh Lisiswati ${ }^{16}$ pada mahasiswa FK UNILA bahwa nilai motivasi ekstrinsik mahasiswa lebih besar daripada motivasi intrinsiknya. Sedangkan Leman ${ }^{19}$ yang meneliti mahasiswa FK UGM mendapatkan hasil yang sebaliknya, yaitu nilai instrinsic goal orientation yang lebih tinggi dibandingkan extrinsic goal orientation.
Instrinsic goal orientation adalah alasan keterlibatan mahasiswa dalam belajar dan melaksanakan tugas karena didasari oleh adanya rasa tantangan, keingintahuan, penguasaan pengetahuan. Mahasiswa yang memiliki instrinsic goal orientation mengindikasikan bahwa mahasiswa melakukan tugas lebih karena tugas itu sendiri sedangkan extrinsic goal orientation adalah alasan keterlibatan mahasiswa dalam belajar dan melaksanakan tugas didasari oleh adanya peringkat, reward, penampilan, evaluasi oleh orang lain dan kompetisi. ${ }^{15}$

Meskipun hasil uji statistik menunjukkan hubungan lemah, tetapi hasil dapat dikatakan bahwa mahasiswa yang memiliki persepsi yang cenderung positif mengenai lingkungan pembelajaran klinik, juga memiliki motivasi belajar yang tinggi. Karabulut et al..$^{20}$ mengevaluasi lingkungan belajar klinik dan mengkaji hubungan lingkungan belajar klinik dengan motivasi akademik mahasiswa keperawatan. Hasil yang diperoleh mendukung penelitian ini, yaitu motivasi akademik mahasiswa baik ketika kualitas lingkungan belajar klinik bagus.

Lingkungan belajar menciptakan suasana belajar yang mempengaruhi motivasi mahasiswa dan strategi belajar. Motivasi akan mengarahkan perilaku dan usaha mahasiswa yang terlihat dari cara mahasiswa memilih suatu strategi belajar tertentu (surface approach atau deep approach). Pemilihan strategi belajar tersebut kemudian mempengaruhi hasil belajar yang didapatkan. Untuk itu, diperlukan lingkungan belajar yang baik yang mendukung proses belajar mahasiswa. ${ }^{7}$ Jika lingkungan mendukung untuk belajar maka individu akan belajar dengan lebih baik. Individu melalui proses interaksi sosial akan mengamati perilaku lingkungan di sekitarnya dan belajar halhal yang akan mempengaruhi motivasi. ${ }^{6}$

\section{KESIMPULAN}

Terdapat hubungan positif yang lemah antara persepsi mahasiswa mengenai lingkungan belajar klinik dan motivasi belajar mahasiswa. Komponen penting dalam pembelajaran klinik adalah peran kepala ruang sebagai manajer ruangan sekaligus sebagai pembimbing yang mendorong terwujudnya 
kualitas pelayanan dan pembelajaran klinik, kesiapan mahasiswa sebelum memasuki tahap pendidikan klinik dan pengalaman belajar klinik yang sesuai dengan kebutuhan mahasiswa.

\section{SARAN}

Berdasarkan hasil penelitian ini, perlu menjadi perhatian bahwa lingkungan belajar klinik perlu disiapkan dengan baik untuk memenuhi kebutuhan dan meningkatkan motivasi belajar mahasiswa. Institusi pendidikan sebaiknya melibatkan kepala ruang yang digunakan sebagai tempat praktek dalam kegiatan koordinasi dan pelatihan-pelatihan terkait pendidikan klinik. Selain itu, institusi pendidikan sebaiknya merencanakan program untuk meningkatkan kesiapan mahasiswa memasuki pendidikan klinik termasuk memberikan pelatihan bagi mahasiswa dalam mengatasi kecemasan di lahan praktek terutama strategi menghadapi ujian. Demikian juga, desain kurikulum pendidikan klinik perlu dirancang dengan baik supaya menarik, memenuhi kebutuhan, dan memicu belajar mahasiswa.

\section{UCAPAN TERIMAKASIH}

Ucapan terimakasih disampaikan kepada dr. Rossi Sanusi, MPA, Ph.D dan dr Tridjoko Hadianto, DTMH, M.Kes yang telah memberikan arahan dan masukan untuk peneliti.

\section{DAFTAR PUSTAKA}

1. Schunk DH. Teori-teori pembelajaran: perspektif pendidikan. Edisi 6. Pustaka Pelajar; 2012.

2. Fry $\mathrm{H}$, Ketterdge $\mathrm{S}$, Marshall S. Handbook teaching and learning: Strategi peningkatan mutu pendidikan di perguruan tinggi. Edisi pertama. Bandung: Zanafa; 2013.

3. Douglass C, Morris SR. Student perspectives on self-directed learning. Journal of the scholarship of teaching and learning, 2014;14(1):13-25.

4. D'Souza MS, Venkatesaperumal R, Radhakrishnan J, Balachandran S. Engagement in clinical learning environment among nursing students: Role of nurse educators. Open Journal of Nursing. 2013;3:25-32.

5. Rotgans J. Schmidt HG. The intricate relationship between motivation and achievement: Examining the mediating role of self regulated learning and achievement-related classroom behavior. International Journal of Teaching and Learning in Higher Education. 2012;24(2):197-208.

6. Rose, S. Academic success of Nursing student: Does Motivation matter? Teaching and Learning in Nursing. 2011;6:181-4.

7. Emilia O. The Relationship between The Clinical Learning Environment and The Approaches To Learning of Medical Student [Dissertation] Doctor Philosophy, Medical education School of Publich Health and Community Medicine Faculty of Medicine The University of New South Wales; 2003.

8. Rahmani A, Zamanzadeh V, Abdullah F, Bani ML, Hassanpour S. Clinical learning environment in viewpoint of nursing student in tabriz university of medical sciences. Iran Journal Nursing Midwifery Res. 2011;16(3):253-6.

9. Nasrin H, Soroor P, Soodabeh J. Nursing Chalenges in Motivating Nursing Student through Clinical Education: A Grounded Theory Study. Nursing research and Practice, 2012.

10. Kim KH, Lee AY, Eudey L, Dea MW. Improving Clinical Competence and Confidence of Senior Nursing Students through Clinical Preceptorship. International Journal of Nursing, 2014;1(2):183-209.

11. Lawal J, Weaver S, Bryan V, Lindo JLM. Factors that influence the clinical learning experience of nursing student at a Caribbean school of nursing. Journal of Nursing Education and Practice. 2015;6(4):32-9.

12. Kaphagawani NC, Useh U. Analysis of Nursing Students Learning Experiences in Clinical Practice: Literature Review. Ethno Med, 2013;7(3):181-5.

Saarikoski M, Leino H-K. The clinical .13 learning environment and supervision by staff nurse: developing the instrument. International .Journal of Nursing Studies. 2001;39:259-67

14. Hasan SM. Hubungan antara persepsi mahasiswa terhadap lingkungan belajar klinik dengan pencapaian kompetensi praktik klinik keperawatan di akademi keperawatan luwuk. Tesis S2 IPK Fakultas Kedokteran Universitas Gadjah Mada; 2012.

15. Pintrich PR. A Conceptual framework for assessing motivation and self regulated learning in college student. Educational Psychology Review. 2004;16(4):385-407.

16. Lisiswati, R. Hubungan Skor Mind Map Rubric (MMR) Dan Hasil Belajar Mahasiswa Fakultas 
Kedokteran Universitas Lampung. Tesis S2 IPK Fakultas Kedokteran Universitas Gadjah Mada; 2013.

17. Frankel A. What leadership styles should senior nurse develop? This is an extended version of the article published in Nursing Times. 2008;104(35):234.

18. Elgicil A, Sari HY. Determining Problems Experienced By Student Nurses In Their Work With Clinical Educators In Turkey. Nurse Education Today. 2007;27:491-8.
19. Leman MA. Persepsi Mahasiswa Mengenai Lingkungan Belajar, Motivasi Belajar, Strategi Belajar, dan Hasil Belajar Di Fakultas Kedokteran Universitas Gadjah Mada Yogyakarta. Tesis S2 IPK Fakultas Kedokteran Universitas Gadjah Mada; 2014.

20. Karabulut N, Aktas YY, Alemdar DK. The relationship of clinical learning environment to nursing students' academic motivation. Kontakt, 2015;17(1):9-15. 